\title{
The Aromatization of Propene Via Nano-Size HZSM-5
}

\author{
Wayne Seames ${ }^{1,}$ *, Swapnil Fegade ${ }^{1}$, Inna Sakodynskaya ${ }^{2}$, Darrin Muggli ${ }^{3}$, Brian Tande ${ }^{1}$, \\ Alena Kubátová ${ }^{4}$, Evguenii Kozliak ${ }^{4}$ \\ ${ }^{1}$ Department of Chemical Engineering, University of North Dakota, Grand Forks, USA \\ ${ }^{2}$ Department of Chemistry, Moscow State University, Moscow, Russia \\ ${ }^{3}$ Engineering Department, Benedictine College, Atchison, USA \\ ${ }^{4}$ Department of Chemistry, University of North Dakota, Grand Forks, USA
}

Email address:

wayne.seames@ndus.edu (W. Seames), fegade.swapnil@gmail.com (S. Fegade), innnas@gmail.com (I. Saskodynskaya), dmuggli@benedictine.edu (D. Muggli), brian.tande@ndus.edu (B. Tande), alena.kubatova@ndus.edu (A. Kubátová), evguenii.kozliak@ndus.edu (E. I. Kozliak)

${ }^{*}$ Corresponding author

\section{To cite this article:}

Wayne Seames, Swapnil Fegade, Inna Sakodynskaya, Darrin Muggli, Brian Tande, Alena Kubátová, Evguenii Kozliak. The Aromatization of Propene Via Nano-Size HZSM-5. American Journal of Applied Chemistry. Vol. 6, No. 5, 2018, pp. 175-188.

doi: 10.11648/j.ajac.20180605.13

Received: October 17, 2018; Accepted: November 1, 2018; Published: November 28, 2018

\begin{abstract}
Zeolite (ZSM) catalysts are known to convert small-size alkenes, e.g., propene, into aromatic hydrocarbons, specifically benzene, toluene and xylenes (BTX), with both high efficiency and specificity. The efficiency of conventional and hierarchical nano-size ZSM-5 for propene aromatization was compared in this study using a Design of Experiments (DOE) approach combined with detailed product analysis. Contrary to our expectations, the former showed a significantly greater BTX yield than the latter. Analysis of the obtained data by DOE and additional experiments with soybean oil cracking using both catalyst types indicated that a reason for the observed reduced activity of nano-scale zeolites may be tenacious water adsorption, which may reduce the catalyst active site availability to the substrate.
\end{abstract}

Keywords: Aromatization, Zeolite, Nano-Size HZSM-5, Hierarchical Catalyst, Design of Experiments, BTX, ZSM-5

\section{Introduction}

Propene is the most common chemical intermediate for the production of toluene and other simple aromatics [1] and processes involving aromatization of propene and other light aliphatic hydrocarbons have been developed [2]. While it is most commonly produced by the dehydrogenation of propane, relatively high concentrations of propene and propane are also produced as a by-product during the noncatalytic cracking triglyceride oils (TG oils) such as soybean oil, canola oil, algae oil, etc. for biofuel production [3-5]. Therefore the efficient conversion of propene and other simple alkenes into aromatics may increase the commercial feasibility of renewable fuel processes based on noncatalytic cracking technologies.

Propene is known to be converted to aromatic hydrocarbons with high selectivity in the presence of zeolites, with ZSM-5 being the most frequently used of these catalysts [6]. The reason for this is that the ZSM-5 catalysts are inherently product-specific. Due to the matching size of their crystalline cavity, they almost exclusively produce aromatics of the smallest size, i.e., benzene, toluene and isomeric xylenes (BTX) [7].

While the distinctive pore geometry of zeolites provide many advantages for facilitating catalytic reactions, their rigid crystalline structure, with molecular-size cavities spanning the entire crystal, can limit the diffusion of larger molecules, thus restricting the reactions that can be facilitated. For many renewable fuel-related reaction applications, the primary active surface sites are only able to participate in secondary reactions, since the initial molecules are diffusion-hindered by catalyst pore geometry.

However, the development of so called hierarchical zeolites, in which nano-size crystalline domains with the essential BTX-size pores are embedded into or supported on 
amorphous alumosilicates, may be a way of addressing these diffusional limitations $[8,9]$. Initially, creating such a varied cavity size design required the use of removable organic templates, but the seminal work of [10] provided a simple template-free nano-size zeolite synthesis protocol. This advancement led to a number of successful applications demonstrating the advantages of using nano-size zeolite catalysts, including but not limited to aromatics' production and ranging from alkene isomerization to triglyceride transesterification [7, 11-19].

In most of these applications, the use of nano-size zeolites provided superior performance compared to their traditional analogs. Yet to our best knowledge, to date these catalysts have not been applied to propene aromatization. In this study, we attempted to address this knowledge gap and discovered an unexpected limitation in using nano-size ZSM-5.

\section{Methods and Materials}

\subsection{Catalyst Preparation}

Commercial ZSM-5 $\left(\mathrm{CBV} 2314-\mathrm{SiO}_{2} / \mathrm{Al}_{2} \mathrm{O}_{3}\right.$ ratio $\left.=23\right)$ was obtained in the powder form from Zeolyst International (Conshohocken, PA). Activation of ZSM-5 was achieved by calcination at $500{ }^{\circ} \mathrm{C}$ for 5 hours in air to convert the ammonium form into HZSM-5. X-ray diffraction (XRD) patterns of the catalyst powder were obtained by using a
Phillips X'Pert PRO X-ray diffractometer.

A nano-size HZSM-5 was synthesized following the template-free procedure described by Cheng and co-workers [10]. Transmission electron micrographs (TEM) of the synthesized nano-size HZSM-5 were obtained using a JEOL JEM-2100 microscope. The procedure followed for calcination of the nano-size HZSM-5 was conducted similarly to that of the conventional ZSM-5, described above.

\subsection{Experimental Materials and Methods}

The catalytic reaction experiments to produce aromatic compounds from propene were performed by flowing propene over a fixed catalyst bed in a continuous downflow reactor. This reactor had an inner diameter of $1 \mathrm{~cm}$ and a length of $25.4 \mathrm{~cm}$. as shown in Figure 1. The fixed catalyst bed was prepared by loading an appropriate amount of catalyst on quartz wool in the reactor. The amount of quartz wool was kept constant for all the experimental runs. A type $\mathrm{K}$ thermocouple measured the temperature at the center of the catalyst bed and a Eurotherm 2116 controller provided a feedback to a tube furnace, which was used to obtain the desired reaction temperature. Separate Aalborg GFC17 mass flow controllers controlled the flow rates of propene and nitrogen, which were obtained at ultrahigh purity concentration from Praxair (Danbury, CT).

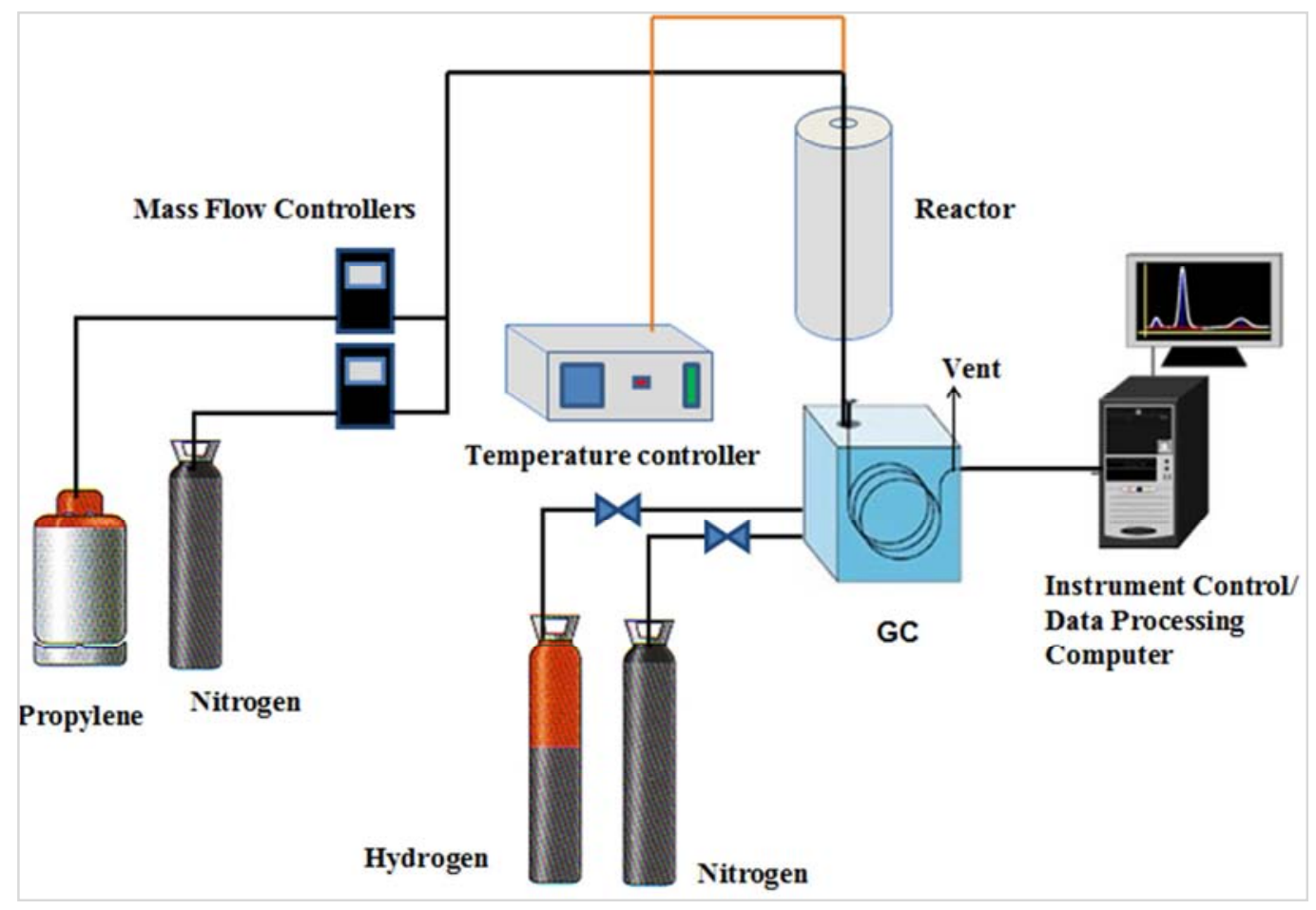

Figure 1. Schematic diagram of the catalyst activity test apparatus.

An in-line gas chromatograph (described under Analytical Methods, below) measured product concentrations in the reactor effluent. For every experimental run, steady state was achieved when the aromatics' concentration in the product stream became constant. Once steady state was achieved, four GC sampling analyses were averaged to determine product yields and propene conversion.

A two-level, three-factor (temperature, propene concentration and catalyst loading), full-factorial design of experiments (DOE) was used and repeated with both 
conventional and nano-size HZSM-5 catalysts. Fresh catalyst was loaded into the reactor for each experimental run.

Select TG oil cracking experiments (using soybean oil obtained from Northwood Mills, Northwood, ND) were conducted with both traditional and nano-size HZSM-5 in a batch mini-reactor ( $3 \mathrm{~mL}$ volume) at $420{ }^{\circ} \mathrm{C}$. The purpose of these experiments was to compare the performance of the nano-size catalyst to the traditional catalyst with a wellstudied feedstock and at previously well-known conditions. These experiments were designed to verify the activity of the catalyst and provide a baseline to insure that the effects observed during the aromatization reactions were not due to an undetected defect in catalyst synthesis.

\subsection{Analytical Materials and Methods}

An in-line gas chromatograph (SRI 8610C), fitted with a flame ionization detector (GC-FID) and Alltech Hayesep Q $80 / 100$ column, measured product concentrations in the reactor effluent (Figure 1). Separation of peaks was obtained using the following temperature program: initiation at $35^{\circ} \mathrm{C}$ for $3 \mathrm{~min}$, then ramp at $40{ }^{\circ} \mathrm{C} / \mathrm{min}$ to $120{ }^{\circ} \mathrm{C}$, then constant temperature for $45 \mathrm{~min}$. For GC sampling analysis, an automatic gas sampling valve injected $1.00 \mathrm{~mL}$ of sample into a GC column. The sampling frequency was $50 \mathrm{~min}$ and each activity run continued for $400 \mathrm{~min}$.

Analysis of the products of batch soybean oil cracking was conducted following the analytical protocol developed specifically for these types of analysis by Štávová and coworkers [20]. The essence of this method is the detailed analysis of the entire homology profile of all GC-elutable hydrocarbons (using FID detection) with a limited number of chromatographic standards, although the identification of all BTX products was confirmed using the match of retention times with the corresponding external standards.

\section{Results and Discussion}

\subsection{Characterization of Nano-size HZSM-5}

Figure 2a presents the XRD pattern of the nano-size HZSM-5 catalyst powder. These patterns feature two distinct peaks between 2 Theta positions of 5-10 as well as showing well defined peaks between positions 22-25. Small patterns are also observed around 2 Theta positions of 13-17, 30, 4547. These patterns match the positions corresponding to the HZSM-5 framework structure [10, 15] thus confirming that the prepared catalyst is a HZSM-5 type zeolite.

Figure $2 \mathrm{~b}$ shows a transmission electron micrograph of the nano-size catalyst. This image suggests that the particle size of the synthesized ZSM-5 is in a range of 20-50 nm and compares favorably to the corresponding images reported by Cheng and coworkers [10]. Catalyst agglomeration is likely due to adsorption of water out of the air or possibly due to van der Waal attractive forces. However, this agglomeration would not be expected at the elevated reaction temperatures reached in the current study's experiments and thus should not be a factor for propene aromatization.

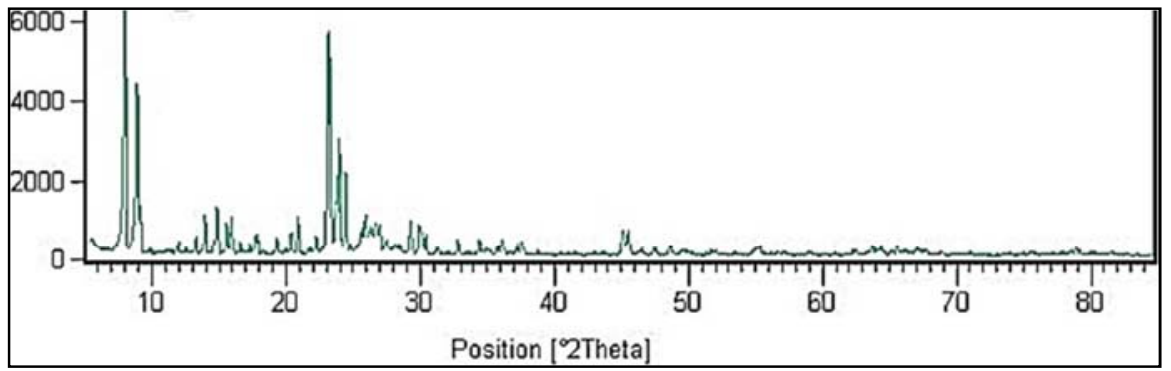

(a)

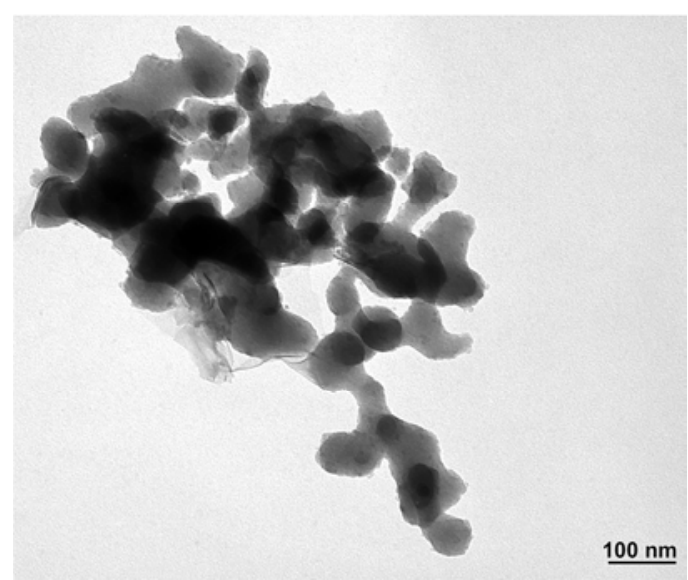

(b)

Figure 2. (a) XRD) pattern and (b) TEM image of the synthesized nano-size HZSM-5 catalyst. 


\subsection{Comparative Catalyst Performance}

Table 1 and Figure 3 show a comparison of the conversion of propane into BTX for both nano-size and traditional HZSM-5 catalysts. We were surprised to find that BTX yields from the Nano-size ZSM-5 were lower than those from the conventional catalyst. Based on previous work with other reaction systems, the higher accessibility of the nanosize catalyst was expected to increase reaction intermediate formation on the zeolite surface, leading to increased cyclization on the Brønsted acid sites inside zeolite pores.

Table 1. Propene Aromatization Experimental Conditions and Results ${ }^{a}$.

\begin{tabular}{|c|c|c|c|c|c|c|c|}
\hline \multirow{2}{*}{ Run } & Temperature & Propene Concentration & Catalyst loading & Benzene Yield & Toluene Yield & Total Xylenes Yield & Total BTX Yield \\
\hline & $\left({ }^{\circ} \mathrm{C}\right)$ & $(\operatorname{vol} \%)$ & (g) & \multicolumn{4}{|c|}{ (wt\% C3 Converted) } \\
\hline $15 \mathrm{M}^{\mathrm{b}}$ & \multirow{3}{*}{500} & \multirow{3}{*}{12.5} & \multirow{3}{*}{1} & 8 & 15 & 8 & 31 \\
\hline $1 \mathrm{~N}$ & & & & 9 & 14 & 6 & 29 \\
\hline $13 \mathrm{~N}$ & & & & 9 & 14 & 6 & 29 \\
\hline $2 \mathrm{~N}$ & \multirow{2}{*}{500} & \multirow{2}{*}{12.5} & \multirow{2}{*}{0.5} & 3 & 9 & 9 & 21 \\
\hline $4 \mathrm{~N}$ & & & & 3 & 9.5 & 9.5 & 22 \\
\hline $3 \mathrm{~N}$ & 400 & 12.5 & 0.5 & 1.4 & 7 & 8 & 17 \\
\hline $9 \mathrm{M}$ & \multirow{3}{*}{400} & \multirow{3}{*}{8.9} & \multirow{3}{*}{1} & 3 & 11 & 10 & 24 \\
\hline $5 \mathrm{~N}$ & & & & 2 & 7 & 8 & 17 \\
\hline $11 \mathrm{~N}$ & & & & 2 & 7 & 8 & 17 \\
\hline $11 \mathrm{M}$ & \multirow{3}{*}{500} & \multirow{3}{*}{8.9} & \multirow{3}{*}{1} & 3 & 12 & 10 & 25 \\
\hline $6 \mathrm{~N}$ & & & & 5 & 11 & 7 & 23 \\
\hline $8 \mathrm{~N}$ & & & & 5 & 11 & 7 & 23 \\
\hline $7 \mathrm{~N}$ & 400 & 8.9 & 0.5 & 1 & 6 & 8 & 15 \\
\hline $13 \mathrm{M}$ & \multirow{3}{*}{400} & \multirow{3}{*}{12.5} & \multirow{3}{*}{1} & 4 & 12 & 9 & 25 \\
\hline $9 \mathrm{~N}$ & & & & 2 & 9 & 8 & 19 \\
\hline $12 \mathrm{~N}$ & & & & 2 & 10 & 8 & 20 \\
\hline $14 \mathrm{~N}$ & \multirow{2}{*}{500} & \multirow{2}{*}{8.9} & \multirow{2}{*}{0.5} & 2 & 6 & 6 & 14 \\
\hline $15 \mathrm{~N}$ & & & & 2 & 6 & 7 & 15 \\
\hline
\end{tabular}

a A more complete set of experimental results with a traditional HZSM-5 catalyst can be found in [1]

${ }^{\mathrm{b}}$ Actual experimental run order number for $\mathrm{M}=$ microscale (traditional HZSM-5) experiments and $\mathrm{N}=$ nanoscale catalysts

One possible explanation is that the increase in the ratio of active surface sites to interior Brønsted acid sites for nanosize compared to traditional catalyst results in the formation of a higher concentration of unanticipated by-products, thus reducing the fraction of propene radicals diffusing into the catalyst pores. A likely case is the cleavage of propene into methane and ethene where a portion of the ethane may then undergo hydrogenation to ethane. Figure 4 confirms that the concentrations of methane, ethane and ethene as products from the propene conversion reactions are greater for the nano-size HZSM-5 compared to the traditional HZSM-5. Further evidence supporting this assumption is provided in the next section on DOE.

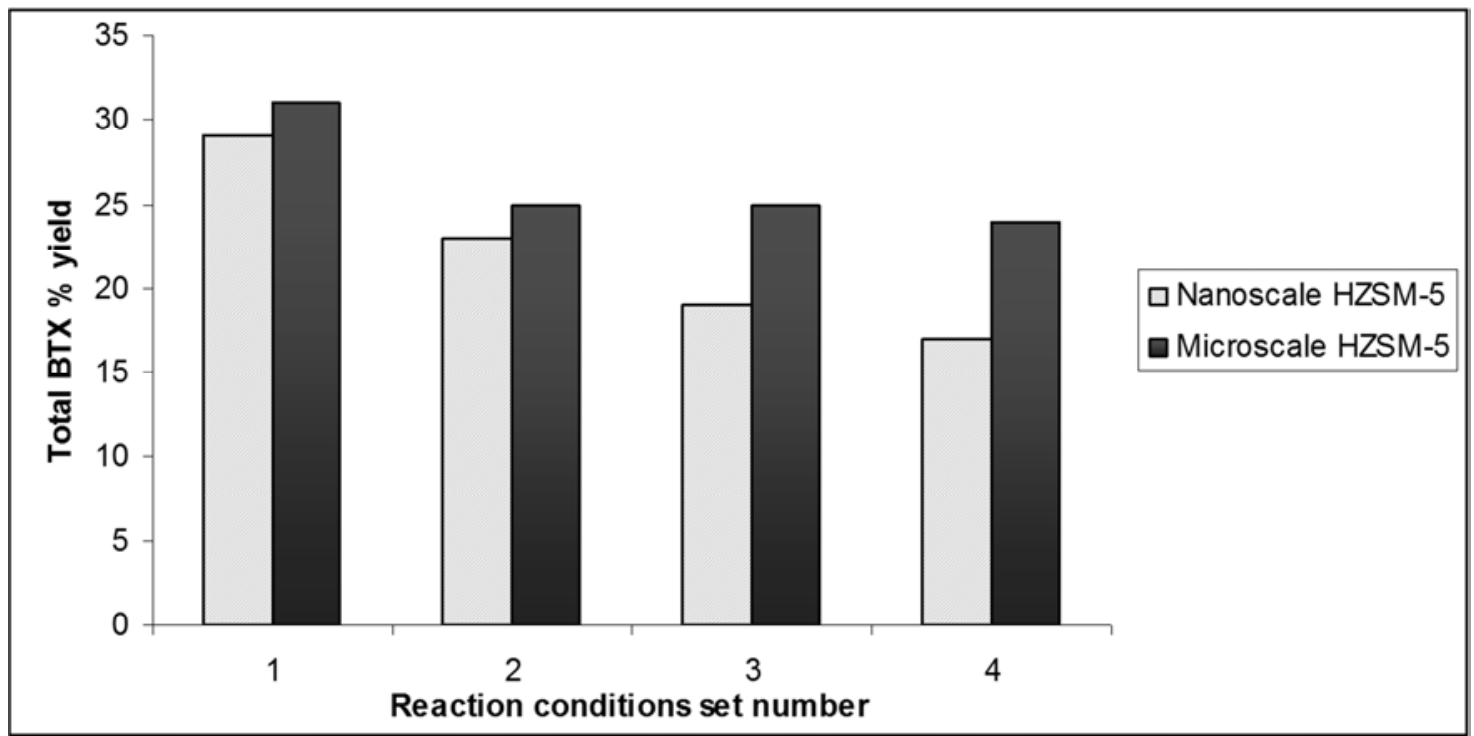

Figure 3. A comparison between the performance of nanoscale and traditional (microscale) HZSM-5 catalysts to facilitate the conversion of propene to aromatics at four different reaction conditions (see Table 1 for specific details). 
However if this explanation is correct, we would still expect higher concentrations of BTX, but perhaps with different relative concentrations of the primary aromatics, as the $\mathrm{C} 1$ and $\mathrm{C} 2$ sized radicals formed by the cleavage reactions should readily diffuse into the zeolite pores and form cyclic compounds. However, the Table 1 results do not support this hypothesis.

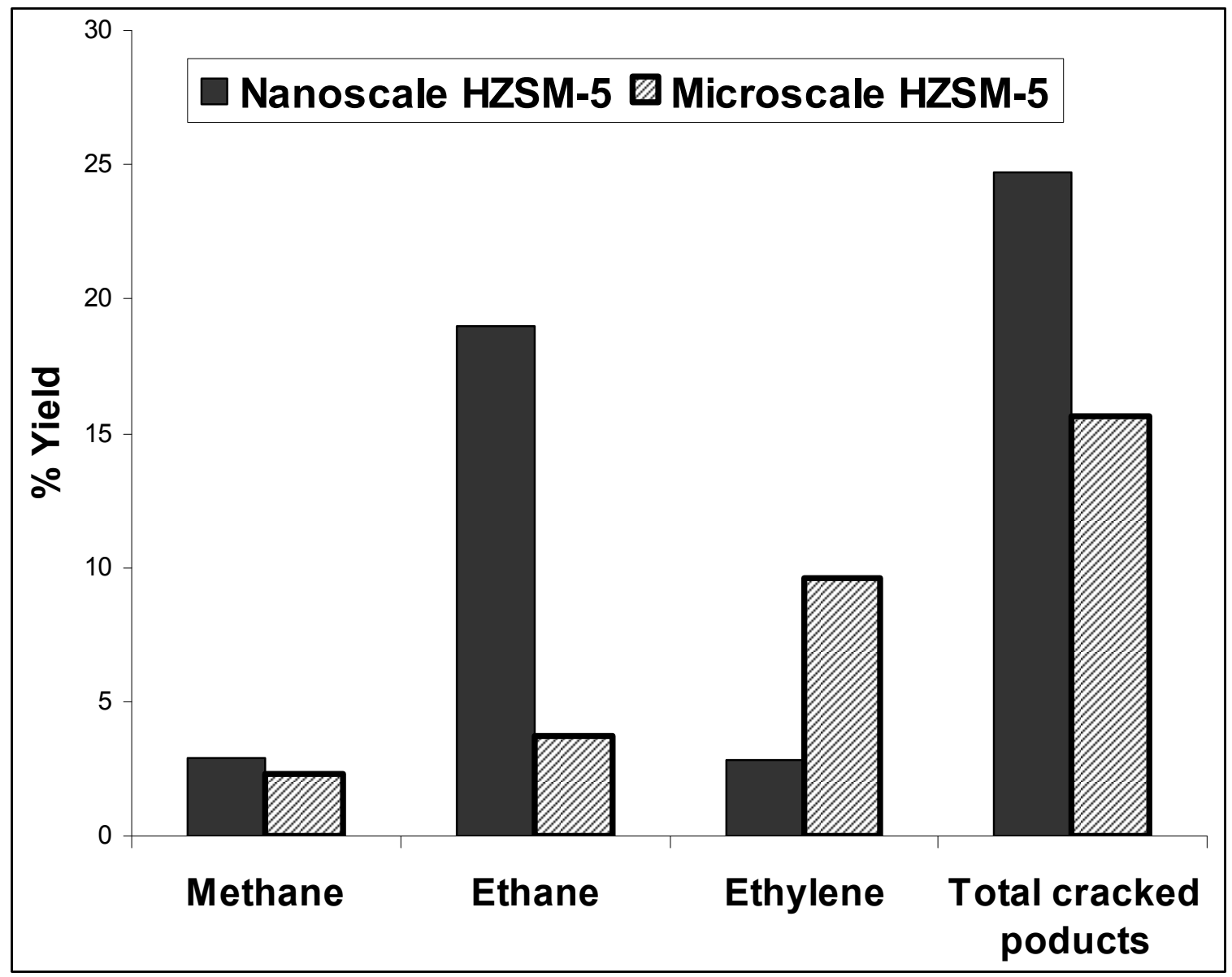

Figure 4. A comparison of the decomposition product yields generated during the aromatization of propene facilitated by nanoscale and traditional (microscale) HZSM-5 catalysts at the same reaction conditions

Given these surprising results, we decided to compare the nano-size and traditional zeolite catalysts in an alternate reaction, one that we have studied more substantially $[1,21$, 22]. In these experiments, catalyst was mixed with soybean oil to form a slurry under anaerobic conditions in a $3 \mathrm{~mL}$ batch reaction system, as described in section 2.2 , above. Catalytic cracking reactions were performed at $420{ }^{\circ} \mathrm{C}$ for a residence time of $20 \mathrm{~min}$ this reactor. The reactor was cooled down to room temperature and then vented. The liquid product was decanted out from the solids (catalyst and coke).

The liquid product from the traditional catalyst experiments was a nearly pure organic liquid product, as was expected from previous work. However, the liquid product from the nano-size catalyst experiments contained a substantial aqueous phase. Such a phase was completely unexpected and cannot be explained by reaction chemistry. Water is not a common by-product of soybean oil cracking reactions and while a small amount of aqueous phase, containing primarily dissolved acetic and propionic acid, may be formed during) non-catalytic cracking [22], such a phase would be reduced or eliminated during zeolite catalytic cracking due to secondary decarboxylation reactions, which are among those catalyzed by zeolites $[3,5]$. The most likely explanation is that, despite extensive calcining at $500{ }^{\circ} \mathrm{C}$, substantial water was present and tightly bound in the pores of the nano-size catalyst, reducing the number of Brønsted acid sites available for cyclization.

\subsection{DOE Factor Effects}

A two-level, three-factor (reaction temperature, propene concentration and catalyst loading), full-factorial DOE was used to explore the nano-size HZSM-5 catalyst reaction domain. The results from these experiments are shown in Table 1. All three factors had a statistically significant positive (in terms of aromatics production) effect on the total concentration of BTX in the final product (see supplemental Figure 1 for details). An increase in all three factors resulted in a significant increase in the BTX yield. Similar effects were observed and explained for the traditional HZSM-5 in a prior study [1]. Thus, the effects of these factors on BTX 
yields are irrespective of catalyst size scale.

Further, the interaction of reaction temperature with propene concentration and the interaction of reaction temperature with catalyst amount also had a statistically significant effect on final BTX concentration (see the Pareto chart and interaction plots in supplemental Figure S1c for details).

The positive (in terms of aromatics production) significant interaction of reaction temperature with propene concentration suggests that the dominant reaction mechanism for aromatization of propene may be a multi-molecular process, where propene is first cleaved into $\mathrm{C} 1$ and $\mathrm{C} 2$ sized radicals at the catalyst surface followed by diffusion into the pores where the fragments combine to form cyclic compounds. Previous work has shown that higher reaction temperature leads to increased propene cleavage for reactions facilitated by conventional HZSM-5 catalyst [1].

The positive (in terms of aromatics' production) interaction of reaction temperature with a higher catalyst loading supports our hypothesis that bound water is interfering with nano-size catalyst pore availability. Since the catalyst used at both low and high loadings is the same, the average active site availability per catalyst particle is likely to be the same. Thus, when the catalyst loading is increased, there is an increase in the number of available active sites to facilitate aromatization reactions.

\subsubsection{The Effect of DOE Factors on Xylene Yields}

In previous work, we found that xylene yield increases significantly with increased catalyst loading when commercially available micro sized HZSM-5 is used [1]. However, the yield of xylene facilitated by the nano-size catalyst actually decreased with increased catalyst loading (see Supplemental Figure S2 for details) while benzene and toluene yields increased.

Two possibilities seem plausible, both based on the difference in pore structure of a nano-size zeolite compared to a traditional zeolite. The pores in a nano-size zeolite have limited connectivity to other pores within the particle. Whereas larger particles contain layers of pore channels attached to each other, which increases the residence time of reactants and product inside of the pores of the zeolite. So one possible explanation of the results is that once an aromatic or aromatic radical is formed in a nanoscale particle, it has less time to interact and react with additional methyl radicals to add functional groups to the basic aromatic ring.

Another possibility is that because xylene molecules formed in a nanoparticle have a lower residence time within the particle, they have a longer average residence time in contact with the external surface of the zeolite (for a comparable bulk residence time within the catalyst bed). The active sites on the external surface of the zeolite may be facilitating the (hydro) dealkylation of xylenes. Under this scenario, an increase in catalyst loading would increase the probability that xylenes formed within the particles would hydrodealkylate into benzene or toluene.

The interaction plot for xylenes (Supplemental Figure S2c) shows that the effect of temperature on xylene yield depends on the catalyst loading. Higher amounts of catalyst at higher temperature led to lower xylene yields which supports the second hypothesis, reduction due to hydrodealkylation.

This same interaction plot also suggests that lower xylene yields will occur when reaction temperature and propene concentration are both increased, which is again contrary to the effect for benzene and toluene yield. This result also supports a reaction pathway that includes xylene formation followed by decomposition into benzene or toluene. This suggests that the nano-size catalyst, under the conditions used in these experiments, may be more effective as a xylene dealkylation catalyst rather as a propene aromatization catalyst.

\subsubsection{Benzene/Toluene Yields and Mechanistic Considerations}

Unlike the xylenes, all three factors (reaction temperature, propene concentration and catalyst loading) have a positive effect on benzene and toluene yield (see supplemental Figures S3 and S4). The interaction plot for the relative yield of toluene (Supplemental Figure S3c) shows that the positive effect of reaction temperature on toluene yield depends on propene feed concentration. However, at the higher level of propene concentration, toluene yields are almost the same, regardless of the reaction temperature, which suggests that the rate of toluene formation is diffusion limited. This supports the hypotheses described in section 3.2 concerning the BTX size pore availability in the nano-size HZSM-5 particles utilized.

\section{Conclusions}

Comparing the efficiency of conventional and nano-size ZSM-5, we observed that, contrary to our expectations, the former had a greater catalytic activity than the latter. Analysis of the data obtained by DOE, particularly the altered specificity observed within the BTX group, as well as the additional experiments conducted with soybean oil cracking, suggest that the observed reduced activity of nano-size zeolites maybe due to their high affinity to water whose adsorption may reduce the catalyst availability to the substrate. Thus, the use of nano-size ZSM-5 may require additional efforts in removing the bound water prior to the catalyst application.

\section{Acknowledgements}

The authors gratefully acknowledge the financial support by the National Science Foundation Experimental Program to Stimulate Competitive Research (NSF EPSCoR) and contributions from Dr. Kanishka Marasinghe of the University of North Dakota, Department of Physics and Astrophysics. 


\section{Appendix}

\section{Pareto Chart of the Standardized Effects \\ (response is Total BTX (\% yield), $\alpha=0.05$ )}

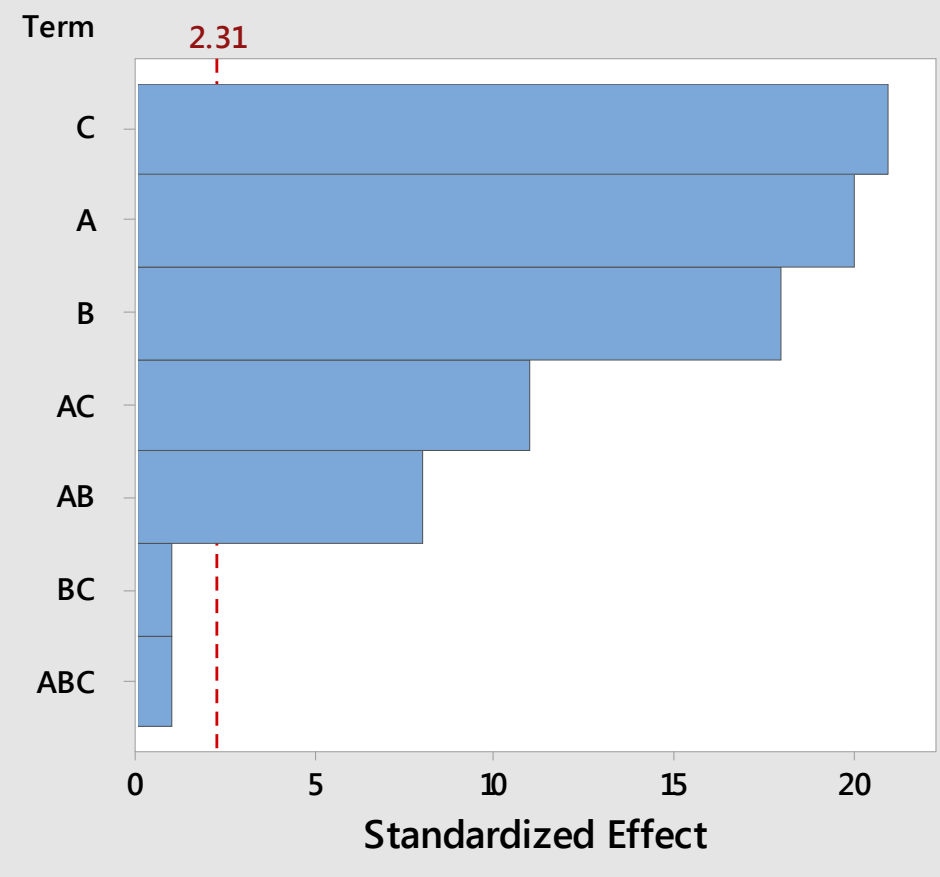

Factor Name

A Temperature $\left({ }^{\circ} \mathrm{C}\right)$

B Propylene Concentration (vol \%)

C Catalyst loading (g)

(a)

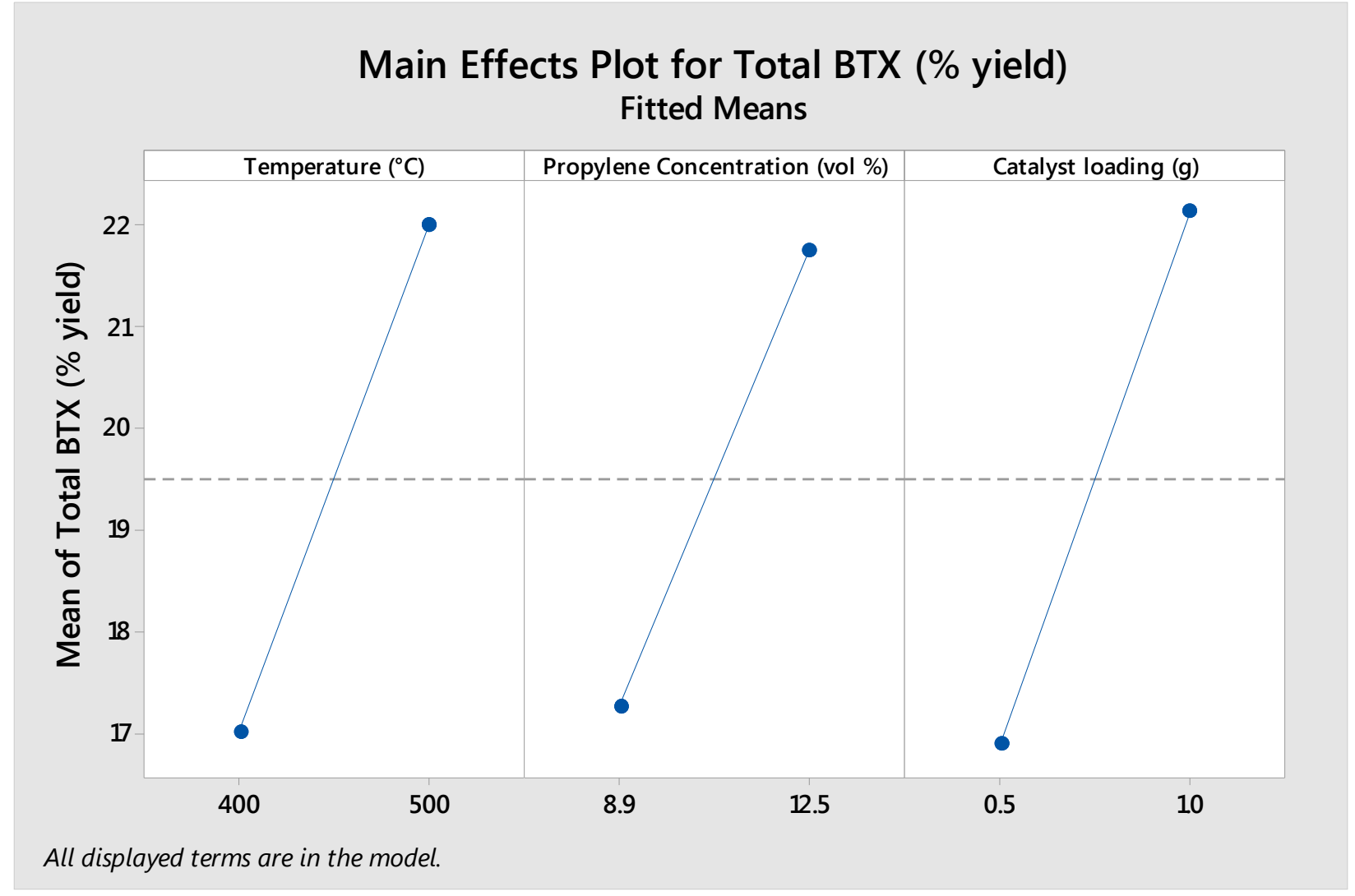

(b) 


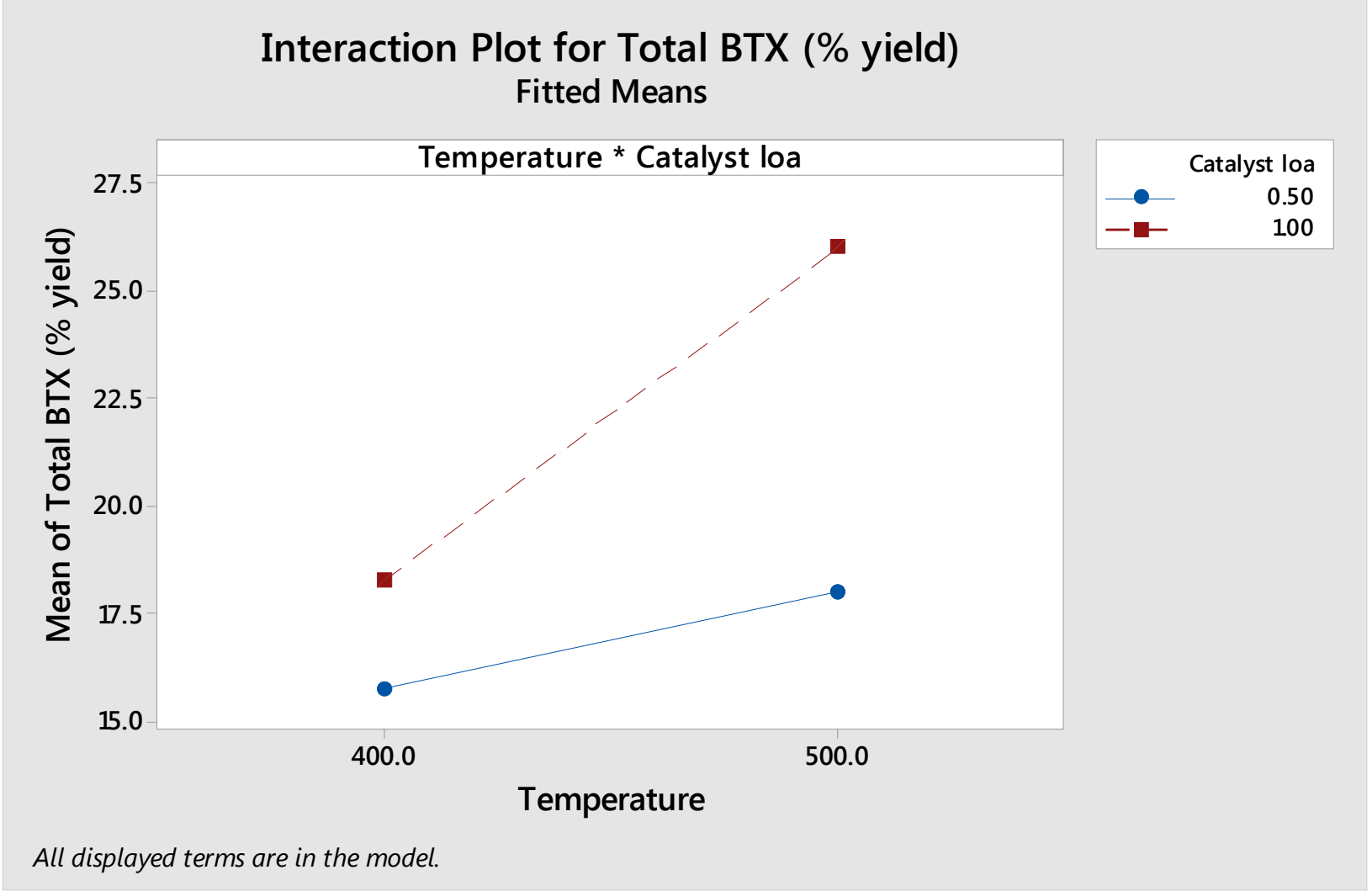

(c1)

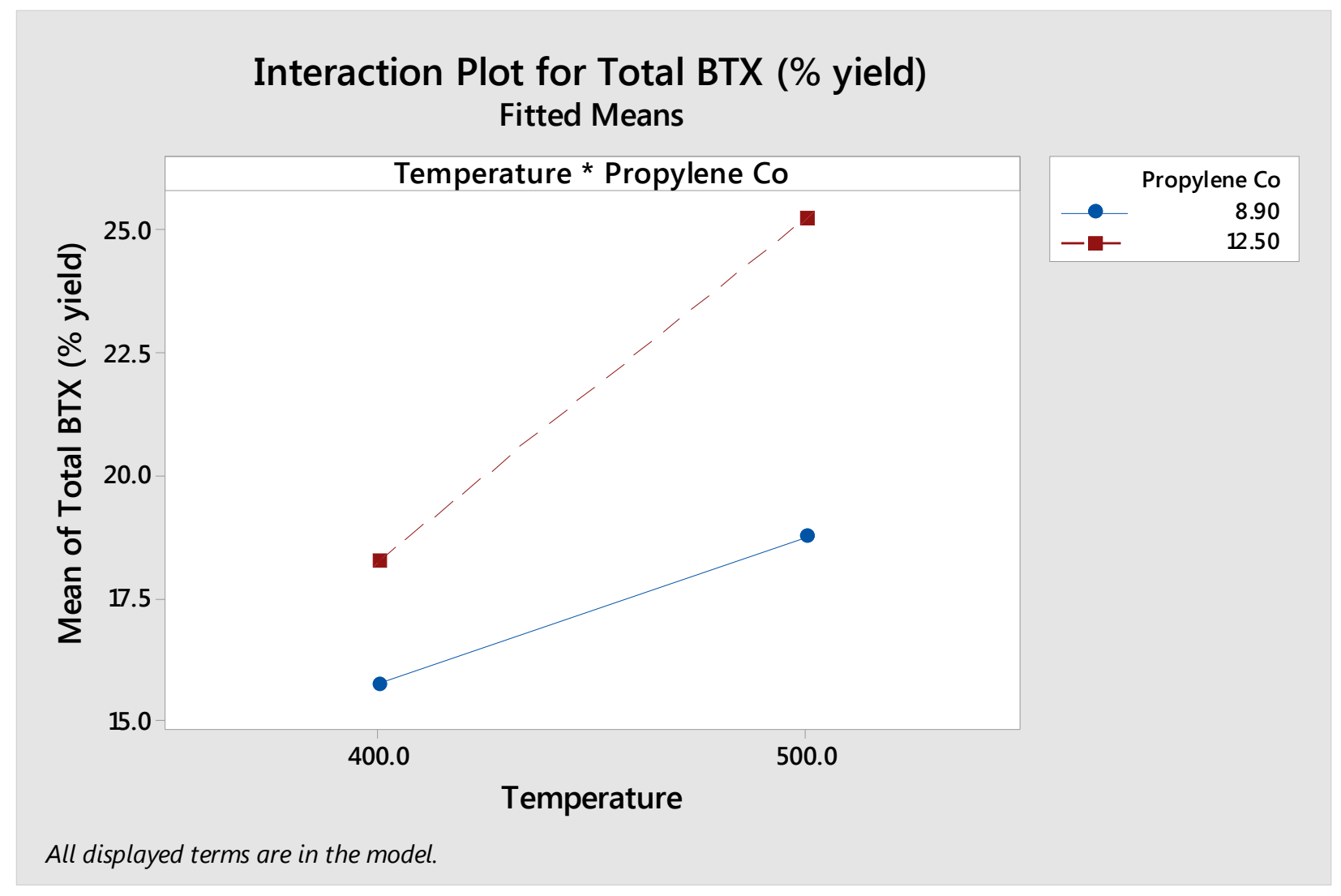

(c2)

Figure A1. (a) Pareto chart, (b) main effects plot, and (c1 \& c2) interaction plots for total BTX yield. 


\section{Pareto Chart of the Standardized Effects}

(response is Xylenes (\% distribution), $\alpha=0.05$ )

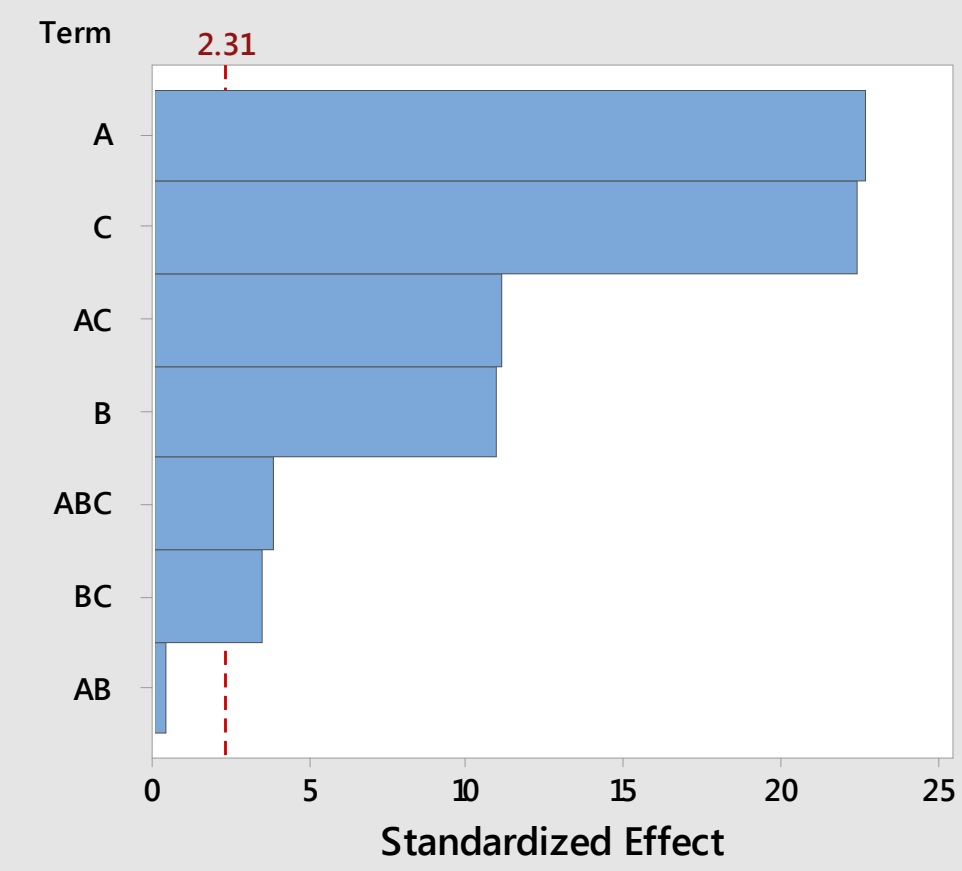

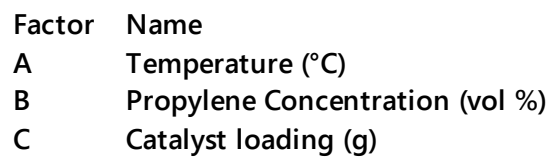

(a)

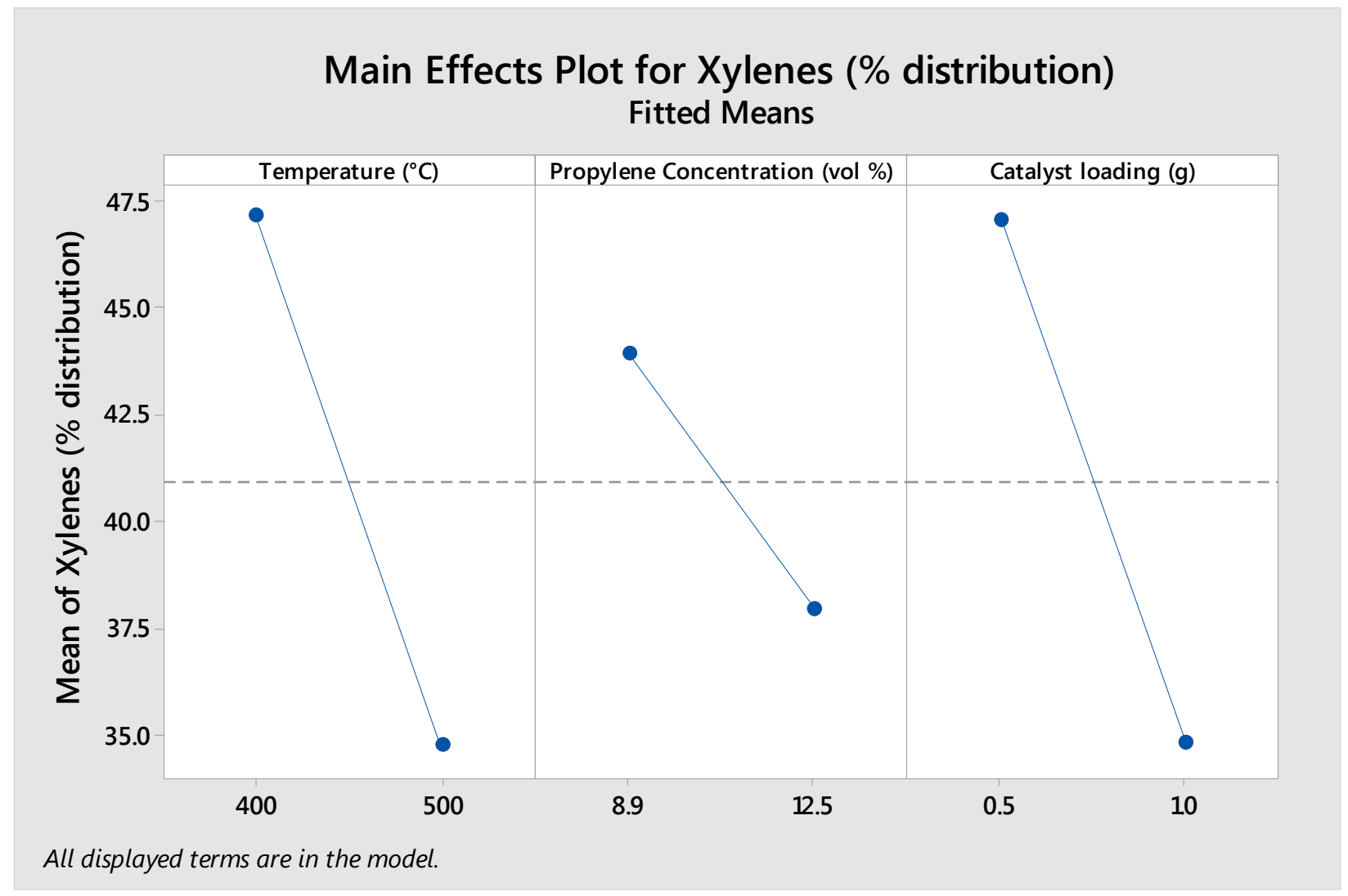




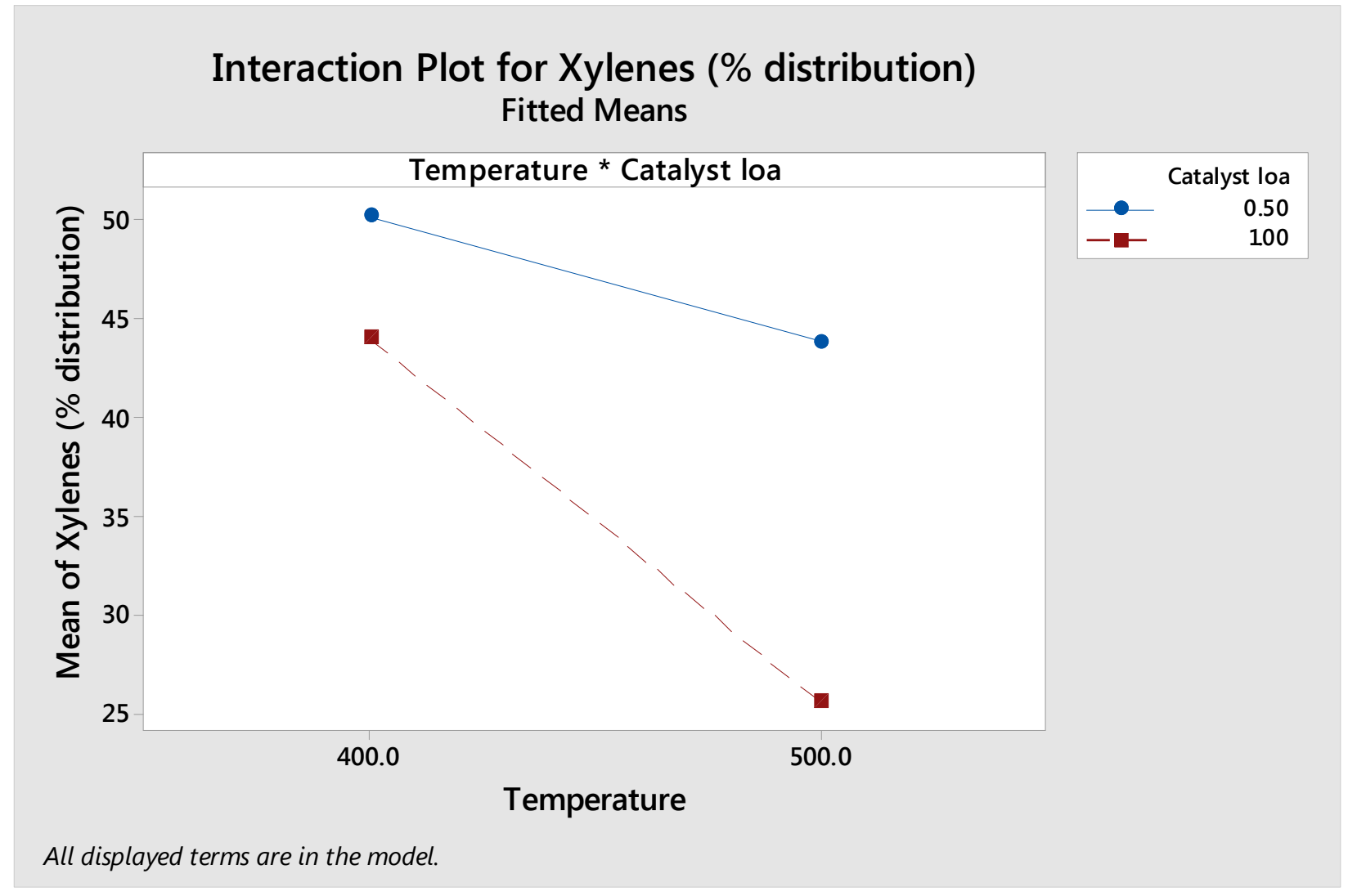

$(\mathrm{c} 1)$

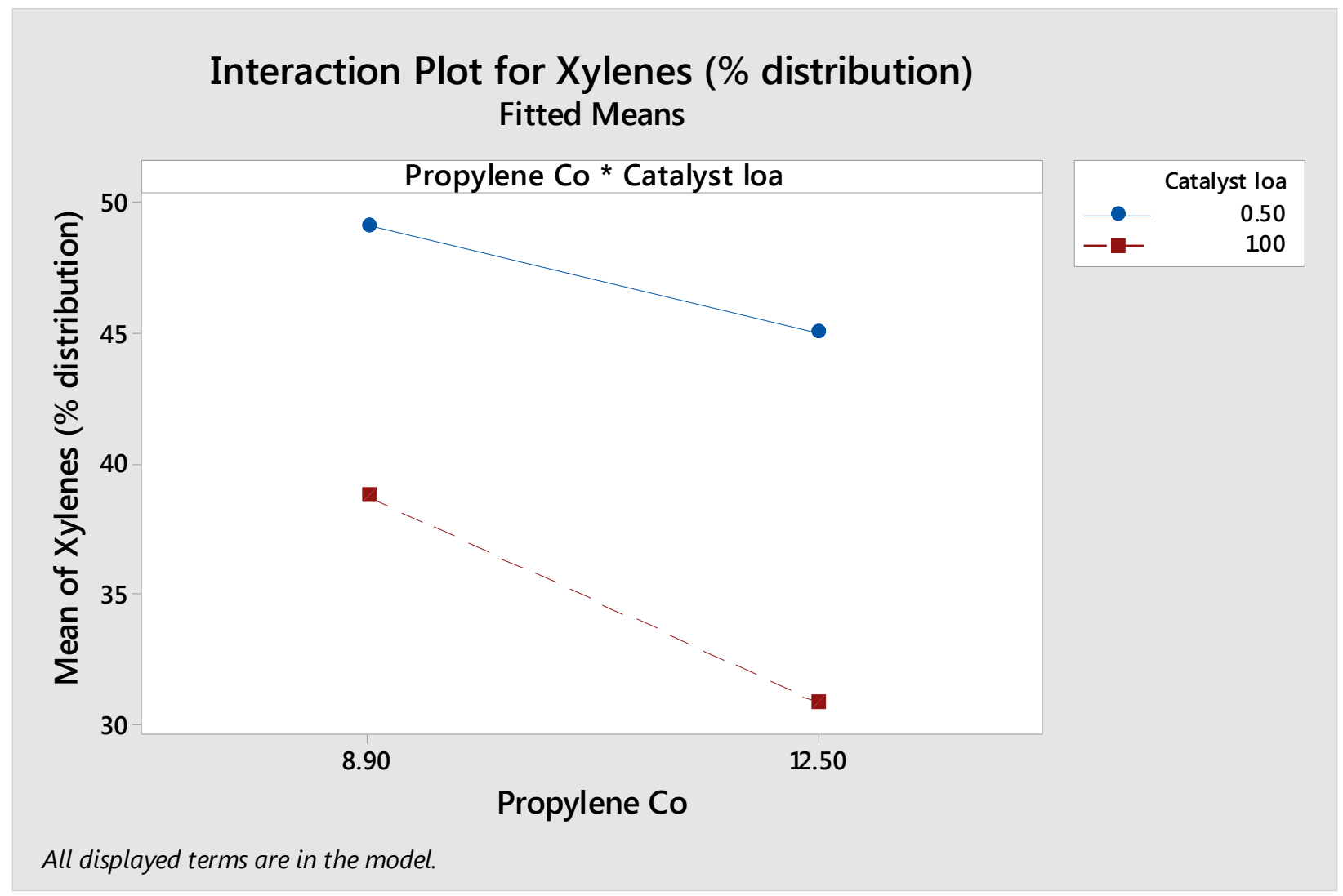

(c2)

Figure A2. (a) Pareto chart, (b) main effects plot, and (c1\& c2) interaction plots for fraction of xylenes. 


\section{Pareto Chart of the Standardized Effects}

(response is Benzene (\% distribution), $\alpha=0.05$ )

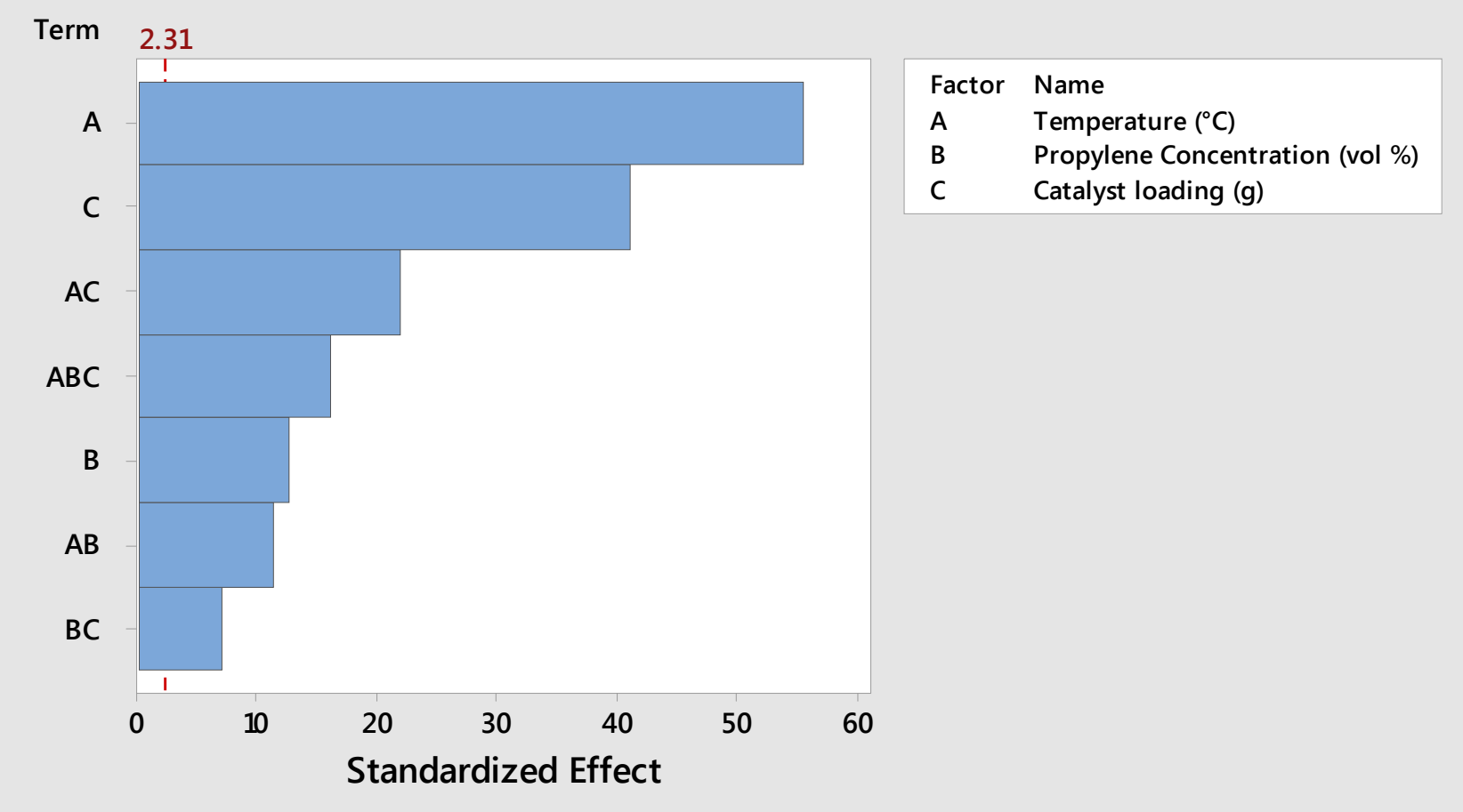

(a)

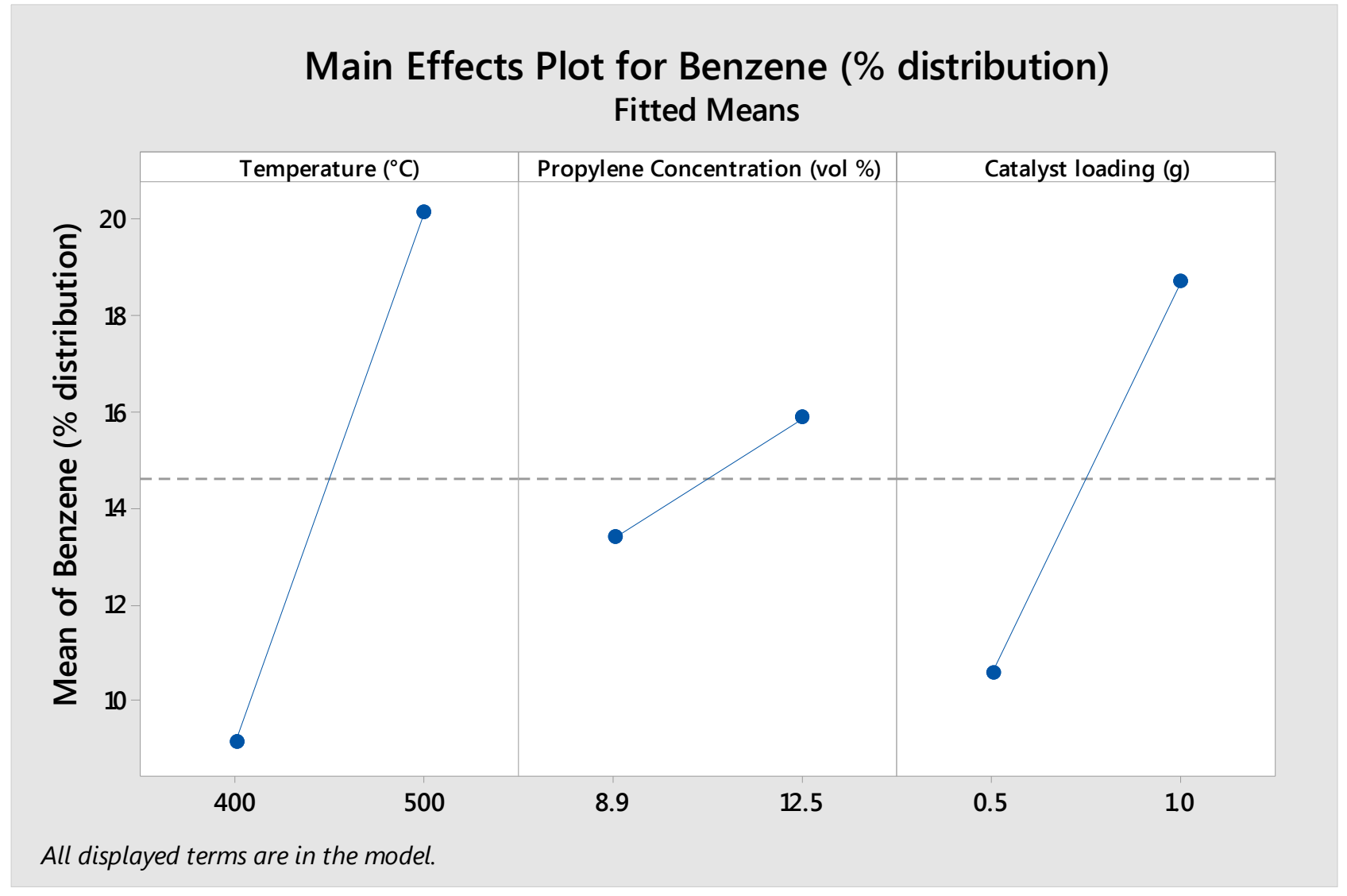

(b) 


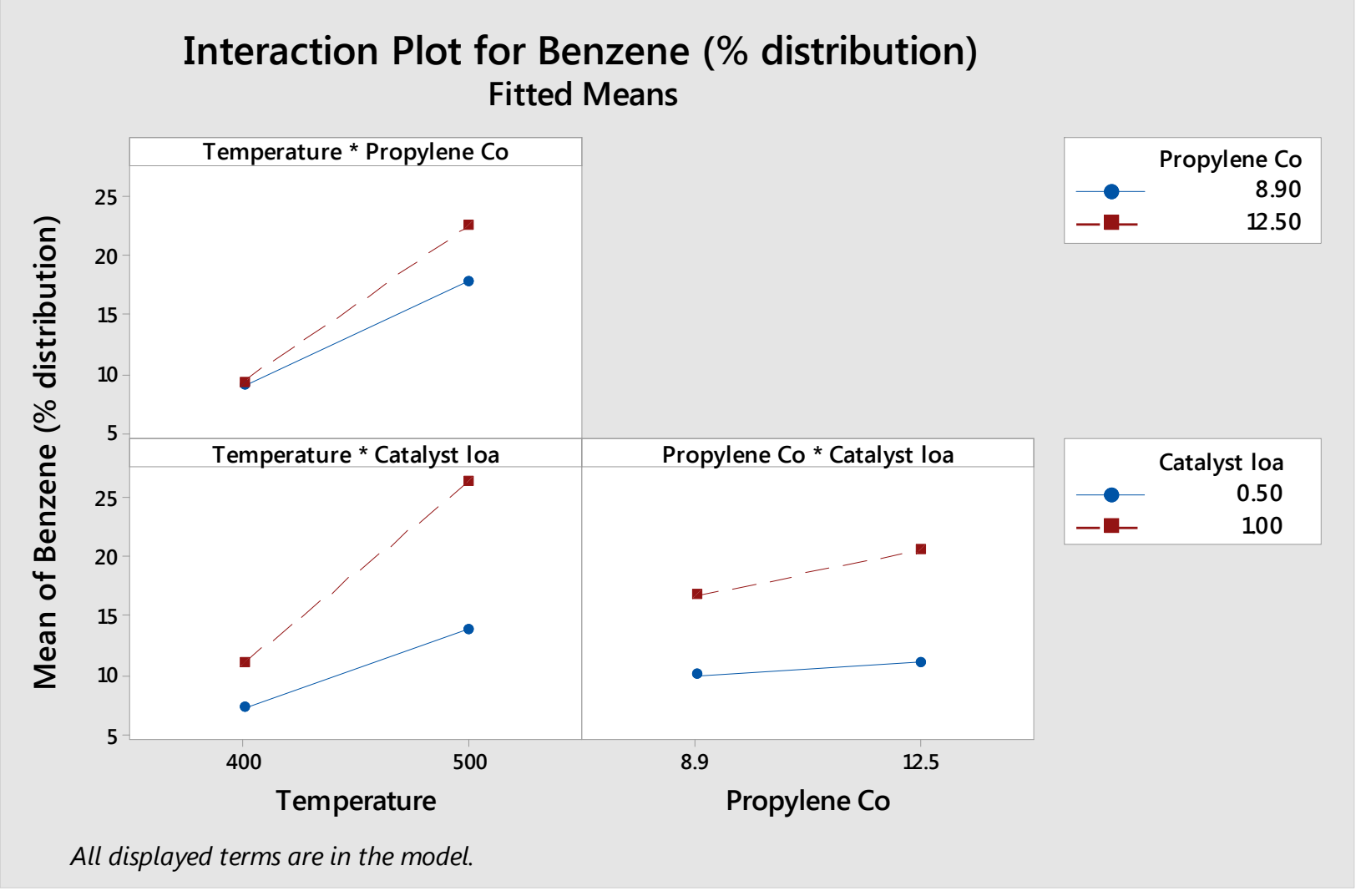

(c)

Figure A3. (a) Pareto chart, (b) main effects plot, and (c) interaction plots for fraction of benzene.

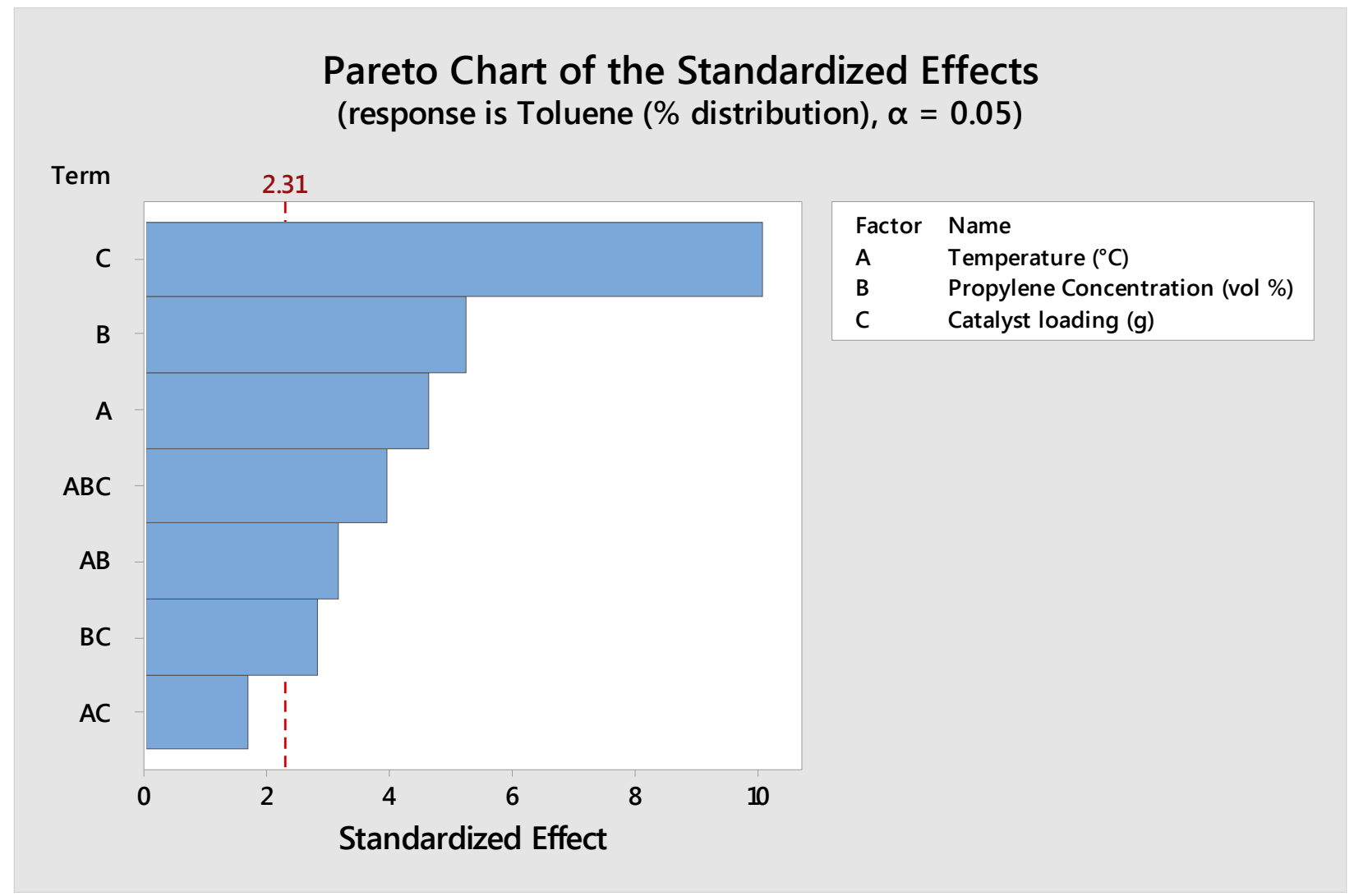




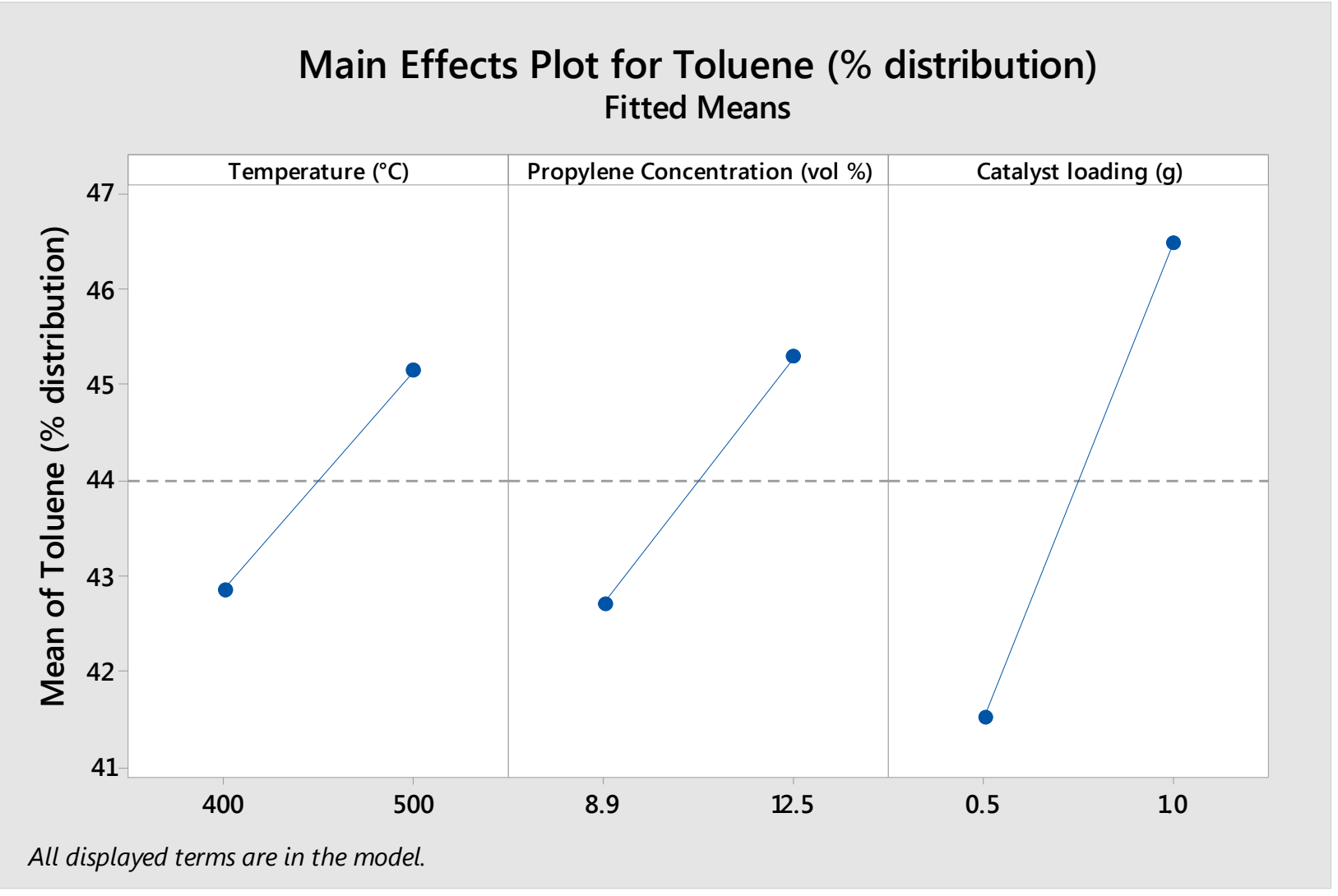

(b)

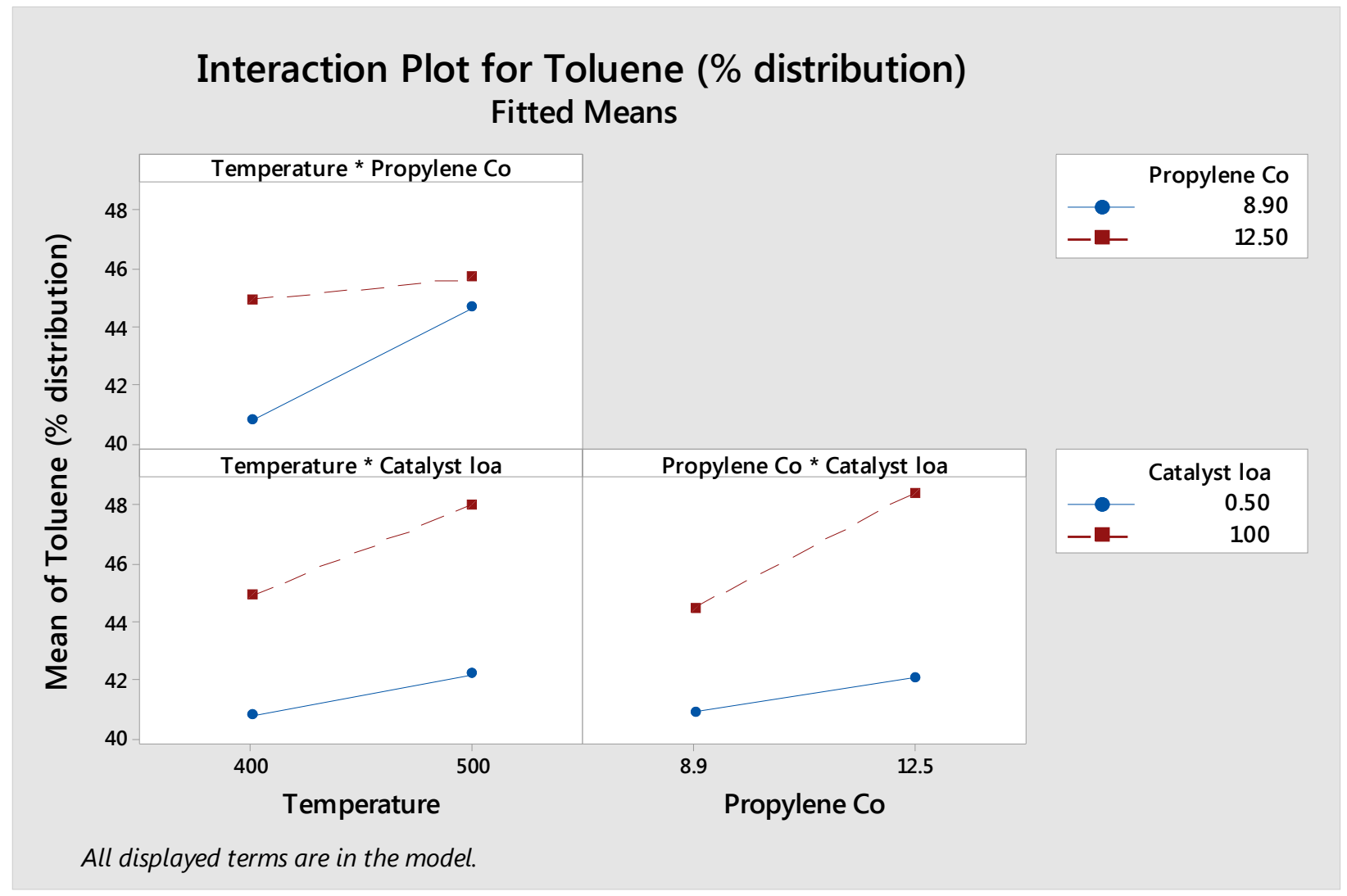

(c)

Figure A4. (a) Pareto chart, (b) main effects plot, and (c) interaction plots for fraction of toluene. 


\section{References}

[1] Fegade, S. L., Tande, B. M., Cho, H., Seames, W. S., Sakodynskaya, I., Muggli, D. S., Kozliak, E. I. (2013). "Aromatization of Propylene over HZSM-5: A Design of Experiments (DOE) Approach." Chem. Eng. Commun., 200(8), 1039-1056

[2] Bhan, A., Delgass, W. N. (2008). "Propane aromatization over HZSM-5 and Ga/HZSM-5 catalysts." Catalysis Reviews Science and Engineering, 50(1), 19-151.

[3] Emori, E. Y., Hirashima, F. H., Zandonai, C. H., Ortiz-Bravo, C. A., Fernandes-Machado, N. R. C., Olsen-Scaliante, M. H. N. (2017). "Catalytic Cracking of Soybean Oil Using ZSM-5 Zeolite." Catalysis Today, 279, 168-176.

[4] Vu, H. X., Schneider, M., Bentrup, U., Dang, T. T., Phan, B. M. Q., Nguyen, D. A., Armbruster, U., Martin, A. (2015). "Hierarchical ZSM-5 Materials for an Enhanced Formation of Gasoline-Range Hydrocarbons and Light Olefins in Catalytic Cracking of Triglyceride-Rich Biomass." Industrial \& Engineering Chemistry Research, 54(6), 1773-1782.

[5] Mo, N., Pennebacker, J., Savage, P. E. (2017) "Hydrocarbon Chemicals from Hydrothermal Processing of Renewable Oils over HZSM-5." Biomass Conversion and Biorefinery, 7(4), 437-443.

[6] Zhang, Ni; Mao, Dongsen; Zhai, Xiaolong Selective conversion of bio-ethanol to propene over nano-HZSM-5 zeolite: Remarkably enhanced catalytic performance by fluorine modification Fuel Processing Technology (2017), $167,50-60$

[7] Schreiber, M. W.; Rodriguez-Nino, D.; Gutierrez, O. Y.; Lercher, J. A. "Hydrodeoxygenation of Fatty Acid Esters Catalyzed by Ni on Nano-sized MFI Type Zeolites." Catalysis Science \& Technology (2016), 6(22), 7976-7984.

[8] Perez-Ramirez, C. H., Christensen, K., Egeblad, K., Groen, J. C. (2008). "Hierarchical zeolites: enhanced utilisation of microporous crystals in catalysis by advances in materials design." Chem. Soc. Rev., 37, 2530-2542.

[9] Zhang, X., Liu, D., Xu, D., Asahina, S., Cychosz, K. A., Agrawal, K. W., Al Wahedi, Y., Bhan, A., Al Hashimi, S., Terasaki, O., Thommes, M., Tsapatsis, M. (2012). "Synthesis of Self-Pillared Zeolite Nanosheets by Repetitive Branching." Science, 336, 1684-1687.

[10] Cheng, Y., Liao, R. H., Li, J. S., Sun, X. Y., Wang, L. J. (2008). "Synthesis Research of Nanosized ZSM-5 Zeolites in the Absence of Organic Template." J. Mater. Process. Technol., 206(1-3), 445-452.

[11] Wang, K., and Wang, X. (2008). "Comparison of Catalytic Performances on Nanoscale HZSM-5 and Microscale HZSM5." Microporous and Mesoporous Materials, 112(1-3), 187192.

[12] Jing, Z., Liang, Z., Guojing, C., Haiyan, W., Min, W., Jun, M. (2008). "The Aromatization Properties of Nano-HZSM-5 Catalyst." Petrol Sci Technol, 26(5), 586-592.

[13] Long, H., Wang, X., Sun, W., Guo, X. (2008). "Conversion of N-Octene Over Nanoscale HZSM-5 Zeolite." Catalysis Letters, 126(3-4), 378-382.

[14] Firoozi, M., Baghalha, M., Asadi, M. (2009). "The Effect of Micro and Nano Particle Sizes of H-ZSM-5 on the Selectivity of MTP Reaction." Catalysis Communications, 10(12), 15821585 .

[15] Viswanadham, N., Kamble, R., Singh, M., Kumar, M., Murali Dhar, G. (2009). "Catalytic Properties of Nano-Sized ZSM-5 Aggregates." Catalysis Today, 141(1-2), 182-186.

[16] Zhu, J., Wu, W. T., Chang, Y., Sun, X. H., Wang, H. Y. (2010). "Application of Nano-HZSM-5 Catalyst on Aromatization of FCC Gasoline." Petrol Sci Technol, 28(1), 7-12.

[17] Khatamian, M., Khandar, A. A., Haghighi, M., Ghadiri, M. (2011). "Nano ZSM-5 Type Ferrisilicates as Novel Catalysts for Ethylbenzene Dehydrogenation in the Presence of N2O." Appl. Surf. Sci., 258(2), 865-872.

[18] Ni, Y., Sun, A., Wu, X., Hai, G., Hu, J., Li, T., Li, G. (2011). "The Preparation of Nano-Sized H[Zn, Al]ZSM-5 Zeolite and its Application in the Aromatization of Methanol." Microporous and Mesoporous Materials, 143(2-3), 435-442.

[19] Al-Ani, A., Darton, R. J., Sneddon, S., Zholobenko, V. (2018) "Nanostructured Zeolites: The Introduction of Intracrystalline Mesoporosity in Basic Faujasite-type Catalysts.” ACS Applied Nano Materials, 1(1), 310-318.

[20] Štávová, J., Stahl, D. C., Seames, W. S., Kubátová, A. (2012). "Method Development for the Characterization of Biofuel Intermediate Products Using Gas Chromatography with Simultaneous Mass Spectrometric and Flame Ionization Detections." Journal of Chromatography A. 1224, 79-88.

[21] Kubatova, A., St’ávová, J., Seames, W., Luo, Y., Sadrameli, A., Smoliakova, I., Kozliak, E. (2012) "Triacylglyceride Thermal Cracking: Pathways to Cyclic Hydrocarbons." Energy \& Fuels, 26(1), 672-685.

[22] Kubatova, A., Geetla, A., Casey, J., Linnen, M. J., Seames, W. S., Smoliakova, I. P., Kozliak, E. I. (2015). "Cleavage of Carboxylic Acid Moieties in Triacylglycerides during Noncatalytic Pyrolysis.” J. Am. Oil Chem. Soc., 92(5), 755-767. 